\title{
Research on the Marketing Communication Activities of Advertisers in China at Current Stage
}

\author{
Gong Cheng* \\ School of Advertising \\ Communication University of China \\ Beijing, China
}

\begin{abstract}
Advertisers are the sponsor and investor of advertising campaigns. Advertisers' investment in marketing communication directly affects the operation and income of media and advertising companies. Therefore, the changes of advertisers' marketing communication activities are closely related to the development of the advertising industry. They are the leading players in the advertising market and their marketing communication activities are one of the important indicators for the overall advertising market. This paper analyses advertisers 'marketing communication activities in the digital media environment and summarizes the features of advertisers 'investment in marketing, media selection and advertising brand communication activities starting from advertisers' marketing activities environment, purposed for providing reference for academic circles and industrial circles.
\end{abstract}

Keywords-advertiser; marketing communication activity; characteristic

\section{INTRODUCTION}

Through the field investigation on the tripartite participants of advertising market activities at current stage, including advertisers, advertising media and advertising companies, this paper makes study and analysis by means of questionnaire survey and the in-depth interview, so as to summarize advertisers' marketing communication activities and their characteristics at current stage.

\section{ENVIRONMENT FOR ADVERTISERS' MARKETING COMMUNICATION}

\section{A. The Economic Environment Is Strange and Changeful, Advertisers Is Conservative for Marketing Investment}

First, the global economic recovery is in a downturn, the European Union and Japan are in deep economic mire, the US has a trend of business upswing, but still at a wait-and-see stage. Second, the domestic economic downturn continues, with the data showing that in 2012, China's GDP growth rate falls down, respectively $7.7 \%, 7.7 \%, 7.3 \%$ in 2012, 2013, 2014; GDP growth reached $6.9 \%$ in 2015 , beyond $7 \%$, officially ending the high-speed growth of average about $10 \%$ in the past 30 years, and again confirming that China's economy is at the key stage of restructuring. ${ }^{1}$ It is expected that this slowing

\footnotetext{
${ }^{1}$ Data source: National Bureau of Statistics
}

\footnotetext{
* Gong Cheng, a Ph.D candidate of School of Advertising of
}

trend will continue. As we all know, advertising is a weatherglass of the economy, the stagnation of economic development will also bring a certain pressure to Chinese advertising market development. According to the ecological research data of Chinese advertising, it is shown that since 2012, China's advertisers have maintained a low investment in marketing communications, and always keep around $9 \% .{ }^{2}$ As the leading of market, advertisers shorten marketing investment, then media advertising costs and advertising revenue are correspondingly reduced, and the overall market is not optimistic.

\section{B. The Macro-control Is Strengthened in Policy, and Advertisers' Marketing Communication Activities Have Been Adjusted}

The policy and legal environment always have a direct or indirect impact on advertisers' marketing communication activities. In recent years, the state administration departments have fully exerted their functions of market management and regulation, and continuously promulgated some relevant laws and regulations such as the new Advertising Law and the Interim Measures for the Supervision and Administration of Internet Advertisements. These relevant policies maintain and purify the advertising market again, to ensure the healthy development of advertisers' marketing communication activities but also bring a certain impact on advertising of drugs, health care products, cosmetics and other special industries. For example, the government at all levels increases the supervision of illegal advertising of drugs, medical treatment and health care products, so the advertising growth rate of these industries have a decline range in the forefront of all industries, with the data showing that in 2014 network advertising costs of drugs keep a basic balance in comparison with the previous year, being 592 million yuan, but slightly up $0.11 \%$ by year-to-year growth rate, which is a cliff-like drop compared with $40.97 \%$ in 2013. (See "Fig. 1") ${ }^{3}$ On the other hand, some policy adjustments for the industry itself will also affect the industry advertisers' investment. For example, the automotive industry is one the top ten advertising investment

\footnotetext{
${ }^{2}$ In this article, related data in the place without special instructions come from 2015-2016 China Advertising Ecological Research, Modern Advertising. February 2016.

${ }^{3}$ Qianzhan Industry Research Institute: "Report on 2015-2020 China 's Advertising Industry Market Outlook and Strategic Investment Planning Analysis.
} 
industries for a long term, while some first-tier cities are forced by traffic congestion have to introduce car purchase limitation policies, which will indirectly affect the automotive industry that had active investment in the past, so they will have an adjustment in marketing investment.

Drug network advertising costs and growth rates in 2010-2014

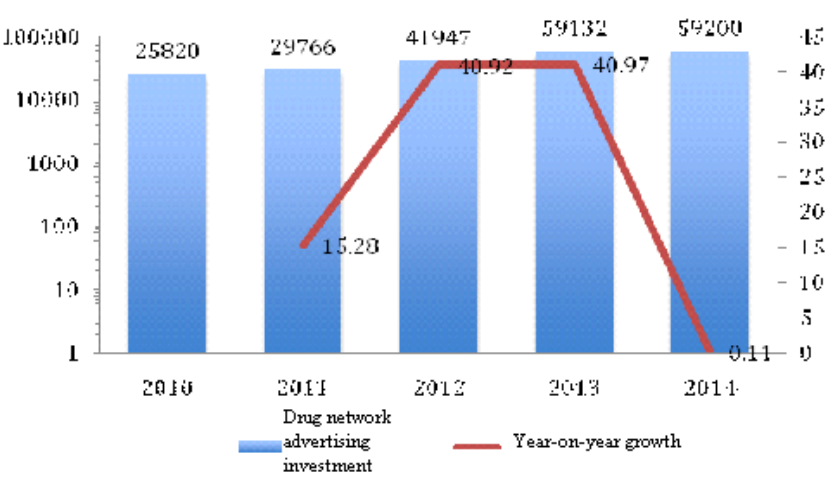

Fig. 1: Drug network advertising costs and growth rates in 2010-2014

Source: Qianzhan.com

\section{The Ecological Reconstruction of Media Brings the Era of} Consumer Empowerment, and Advertisers' Marketing Communication Activities Get More Difficult.

With the constant iteration of technology, digitalization not only infiltrates and covers individual life, but also brings about the ecological environment reconstruction of media, overturns the original unified communication structure of "large media, large communication", and rebuilds new media ecology. The two-way, multi-end, real-time and interactive communication system constructed by digital media resets the status of both communicator and audience, consumers are no longer the "aimed" targets, their free choice is increasing, their volume is constantly enlarged, their consumption structure is upgraded constantly, and the "royal era" of the consumer has arrived. For advertisers, it means that the marketing methodology based on the mass media system that they has referred to gradually gets ineffective, and means that the traditional marketing communication methods, such as hard and wide coverage input is increasingly difficult to attract the attention of consumers, and consumers' decision-making and consumption behavior is difficult to predict. Therefore, the advertisers are full of bepuzzlement on how to plan scientific and rational marketing communication activities, and their willingness of advertising inputting gets little.

\section{MARKETING DELIVERY CHARACTERISTICS OF} ADVERTISERS: STRENGTHEN PRODUCT INNOVATION AND IMPROVE CHANNEL CONSTRUCTION TO HELP MARKETING SPREAD

\section{A. Grasp the "Internet" Opportunity and Promote the Innovation and Upgrade of Products}

Firstly, with rapid rise of the cost of such production factors such as labor force and raw materials in China, the advantage of manufacturing industry in relying on low cost to hold the market begins to disappear. It is the only way which must be passed by enterprises in our country to realize transformation and upgrading through improving product quality, strengthening innovation and realizing brand upgrade. Secondly, in recent years, our country has promoted innovation and upgrading in all walks of life and launched national strategies and positive policies such as the "Internet Plus" action plan, Made in China 2025, support enterprises to "walk out". Advertisers in many industries actively seize the opportunity and return to the basis of marketing and brand, namely the products as well as pay attention to the upgrading and innovation of products. Therefore, on the basis of deeply having an insight into the customers, advertisers make the best of "Internet Plus" technology and continuously try product innovation to meet the requirements of customers. For example, household appliance industry depends on the concept of "Internet of Everything" to explore product innovation, so intelligent household electrical appliance emerges in endlessly.

\section{B. Open Up Multiple Channels to Help the Integration of Marketing Spread and Sales}

With the rapid development of revolutionary technologies such as Internet of things, 3D print and 4G, the traditional channels of enterprises in spread, supply and sales are challenged greatly. The multi level structure of traditional channels declines and the flattening and decentralization in the digital age grows. New channels emerge in endlessly. The consumption custom of customers innovates. The traditional channels of enterprises are encroached on. Moreover, the idea of advertisers in the "depth distribution" of channels is impeding the enterprise marketing transformation. For example, the annual sales of Wahaha reduce 7\% in 2014. One of the important reasons is that the mode of old joint sales channel cannot adapt to new business environment of enterprises.

In face of increasing growth of new business pattern, internet and mobile shopping, instead of sitting still waiting for death, advertisers of many industries conform to the situation and actively transform. Firstly, some advertisers choose the online and offline combination and realize the seamless integration of all channels. It can directly change the flow into sales and connect the offline physical store to close the deal. It is not so important whether the customers select products online or offline. For example, the IKEA had begun to pay attention to the impact of the internet on offline physical stores long before and had added online website and APP mobile terminal to realize brand promotion and successfully attract customers to consume in the store. Besides, advertisers can get the data of channels with the help of internet technologies such as big data, deeply explore the customers through analyzing online behaviors of customers and realize real time data updating, adjust channel inventory. 


\section{CHARACTERISTICS OF AdVERTISERS IN USING MEdia: DEPEND ON FUSION AND SELECTIVE PREFERENCE TO COMPREHENSIVELY “EMBRACE” THE CUSTOMERS}

\section{A. Realize Unbounded Co-fusion of the Media to Effectively Attract the Customers}

The iteration cycle of technology becomes increasingly shorter. The degree of media fragmentation is high. Compared with the traditional media era, the quality and quantity of information acquisition cannot be mentioned in the same breath. It is extremely difficult to accurately and effectively leave a deep impression on the customers. The advertisers care most about how to attract the attention of customers and finish the sales conversion in marketing communication activities. Therefore, the final purpose of advertisers to choose the media in marketing campaign is to comprehensively "embrace" customers, control each contact point with customers, meet or explore consumption needs and help customers to close the deal. Advertisers believe any medium that can effectively spread advertising information can be used by them to realize unbounded co-fusion, no matter the so-called media or digital media.

In recent years, the all media marketing that integrates television, radio, outdoors, internet, mobile operator, social contact and offline joint promotion are recognized by an increasing number of advertisers. For example, the media fusion of CCTV has achieved good effects. The new media advertising attracts the investment of exceeding 600 million from advertisers in the bidding in 2016. ${ }^{4}$ Many satellite televisions also quicken the pace of media fusion to attract advertisers.

\section{B. It Is An Irresistible Trend That the Mobile Internet Media Takes the Lead, Depending on Precision and Interaction to Build Customer-Centered Three-dimensional Marketing}

In recent years, with continuous enrichment of media environment, technologies and services of digital internet are upgraded and optimized unceasingly. New competition pattern and ecological environment gradually form in the media industry. Under the new environment, the audiences vary ceaselessly. The investment from advertisers reduces and disperses. The income of traditional media is shunted. The market shares are divided by the internet and the digital media leading in the mobile internet media. Therefore, under continuous drive of technological innovation, the products and services of mobile internet media have realized rapid upgrade within just a few years. This upgrade brings more possibilities for the marketing communication activities of advertisers. According to the investigation, the mobile internet media has becoming the digital marketing platform that advertisers pay the most attention to. The advertising ecological research of Communication University of China shows in recent years, the proportion of cost spent by advertisers in mobile advertisement

${ }^{4}$ Gu Menglin: Advance Sale of New Media Advertising Products on 2016 Advertising Bidding of CCTV Office Exceeds 600 Million, People's Daily Online, November 19th, 2015 ,

http://media.people.com.cn/n/2015/1119/c40606-27831101.htm continuously rises. It reached the peak of $11 \%$ in 2015 with growing rate of $44.8 \%$.

Compared with internet media and traditional mass media, the innovation of mobile internet media in precision and interaction is more revolutionary. It builds customer-based panoramic three-dimensional marketing. Firstly, it is the scene lock based on the location. Depending on the mobile terminal, advertisers can realize the precise combination of scene with customers through technological means such as the LBS $^{5}$, classify and send product information according to different time, places and requirements of customers, such as the advertisement of intelligent search of Google. When searching the keyword of "pizza", Google will send different product information according to different time and geographical location. Secondly, it is the deep interaction based on "breaking screen". After breaking the boundaries between screens, advertisers can depend on the mobile terminal to build multi-screen and cross-screen deep interaction with customers. For example, the outdoors and mobile terminals cooperate with outdoor media such as residential block TV and subway, place advertisement or purchase information of related products in electronic screen inside the elevator and the subway to encourage customers to actively scan code and participate in the interaction or use technologies such as ibeacon and NFC to send information to customers to attract their attention and realize the interaction. Finally, it is the precise delivery based on data. Advertisers can use mobile internet media such as mobile social network site to collect huge amounts of data and fully dig data, analyze personal characteristics, media exposure, consuming behavior even lifestyle of the audiences to find out target-consumer and precisely match advertising information, media and users and improve the marketing effects.

\section{Focus on High Quality Resources and Invest Large Sum of Money}

Besides, high quality resource is also one of the important factors that advertisers consider in marketing communication activities, including the judgment on aggregative indicators such as the platform and contents. But on the whole, heavyweight platforms represented by CCTV, excellent provincial satellite TV station, popular web portals led by Sina and Sohu, WeChat platform with hundreds of millions of users, video websites led by Youku and Tudou and high quality contents led by the gold IP always let advertisers scramble for, invest large sum of money and pay high attention to.

Take TV media as an example. From the perspective of biding data statistics in 2016, the TV platforms most popular among advertisers are mainly three platforms (Hunan Satellite TV, CCTV and Zhejiang satellite TV). The advertising revenue of satellite televisions and CCTV shows Hunan Satellite TV, Zhejiang satellite TV and Jiangsu satellite TV occupy the top three of provincial satellite televisions with five

\footnotetext{
${ }^{5}$ LBS technology: it is the service based on the location. It refers to a value added service that uses wireless communication network of telecom and mobile operators or external positioning to get the location of mobile phone users and provide corresponding service for users under the support of GIS platform.
} 
billion to ten billion of revenue and realize increase of about $30 \%$. Obviously, they are very popular.

In recent years, popular drama series, reality show, phenomenal variety show, big movie have attracted advertisers to choose and focus on. Firstly, the performance in large TV series is eye-catching. Advertisers invest large sum of money in popular IP TV plays such as the Journey of Flower and Nirvana in Fire and change the forms of sponsor, title sponsorship and product placement. In the TV series of Ode to Joy with the only title sponsor of Beibei net, 2016 maternal and child e-commerce site, the product placement can be seen everywhere, such as the product placement of Volkswagen props, actor's lines and background with the advertising of Vipshop. Secondly, reality show and phenomenal variety IP are also very popular. CCTV and many provincial satellite TV stations in the first echelon have made appealing brand programs broadcasted with different seasons, such as Dad, Where Are We Going? of Hunan Satellite TV, Go Fighting of Dragon TV and Running Man of Zhejiang Satellite TV. These programs are easy to get the investment of advertising of more than 100 million from advertisers. In addition, top-level news programs are also the IP that advertisers pay much attention to, such as the Xinwen Lianbo of CCTV. Thirdly, influenced by many positive factors, the film market of China develops rapidly. Because the environment of the cinema is not easy to be disturbed, the arrival rate of advertisement is high and advertisers also attach importance to it. The advertisement injecting in films increases yearly. The data shows the total income of Chinese movie marketing market in 2015 reaches 3.8 billion, with year-on-year growth rate of $21.1 \%{ }^{6}$ (Shown in "Fig. 2")

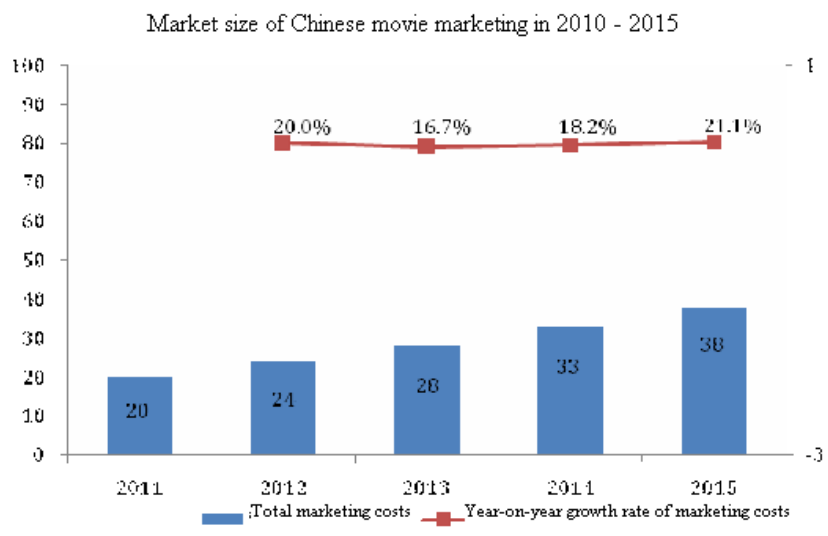

Fig. 2 Market size of Chinese movie marketing from 2010 to 2015

Data source: Entgroup

\section{CONCLUSION}

According to the research and analysis, under the environment of digital media communication, the marketing communication activities of advertisers in our country are in the important stage of transformation. Except for focusing on product innovation and grasping multiple channels, they should pay more attention to the trend of all-around integration.

${ }^{6}$ According to the data calculated by Entgroup 